\section{Prevalence of lactose intolerance in children with recurrent abdominal pain}

Sir,

As there is a great similarity between the symptoms of patients with lactose intolerance and those of children with recurrent abdominal pain, and as in many parts of the world lactose intolerance is one of the most common causes of diarrhoea, meteorism, and abdominal pain in children who are milk drinkers, I compared the prevalence of lactose intolerance in Danish children in whom the diagnosis of psychosomatic abdominal pain had been made with children without abdominal pain. Tolerance tests after oral lactose $(2 \mathrm{~g} / \mathrm{kg}$ body weight) were performed with parental consent on 50 children (22 girls and 28 boys, mean age 9.5 years) with recurrent abdominal pain and on 40 children (17 girls and 23 boys, mean age 9.6 years) without such pain. The diagnosis of lactose intolerance was accepted if abdominal pain and/or diarrhoea developed in association with the test. One of the 50 children fulfilled these criteria for lactose intolerance $(95 \%$ confidence limits: $0.05-10.65)$, while none of the controls did $(95 \%$ confidence limits: $0 \cdot 00-8 \cdot 81)$ (Table).

These criteria cannot be used with complete confidence to diagnose lactose intolerance because an insufficient rise in blood glucose after the lactose load given by mouth may occur in some of the children merely because of a delayed emptying of the stomach. Moreover, some of the children may develop their usual stomach ache solely because of the circumstances of the examination. In consequence, lactose intolerance may be diagnosed too often by these criteria. It is very unlikely, however, that cases of lactose intolerance would not be discovered. Lactose intolerance is not significantly increased in children with recurrent abdominal pain, and it is low in Danish children.

Mogens Fuord Christensen Department of Paediatrics, Herning Central Hospital, DK-7400 Herning, Denmark

Table Results of lactose tolerance tests in patients and controls

\begin{tabular}{lll}
\hline & \multicolumn{2}{c}{ Recurrent abdominal pain } \\
\cline { 2 - 3 } & Children with & Children without \\
\hline $\begin{array}{l}\text { Total } \\
\text { Rise in blood glucose } \\
\quad<20 \mathrm{mg} / 100 \mathrm{ml}\end{array}$ & 50 & 40 \\
$\begin{array}{l}\text { Abdominal pain } \\
\text { and/or loose stools }\end{array}$ & 5 & 5 \\
$\begin{array}{l}\text { Rise in blood glucose } \\
\quad<20 \text { mg/100 ml+abdominal pain } \\
\text { ard/or loose stools }\end{array}$ & 11 & 3 \\
\hline
\end{tabular}

\section{Ocular compression in reflex anoxic seizures}

Sir,

Since the publication of my paper (Archives, 53, 1978, 193), colleagues have asked me two questions.

(1) Does ocular compression invariably induce instantaneous stoppage of the heart? This appeared to be the case in Fig. 9. It is true that in very susceptible children, the onset of asystole is common almost immediately after the start of ocular compression. Thus, out of the current total of 41 anoxic seizures induced in the supine position, in which asystole was 10 seconds or more, the onset was delayed by no more than 1 systole in $25(63 \%)$ and by 2 systoles or less in $36(88 \%)$. However, in less susceptible children the maximum period of asystole may occur at any time during the 10-second period of ocular compression.

(2) Why does this period of ocular compression have to be continued as a routine for up to 10 seconds? A most important reason is that the induction of a visible anoxic seizure has a most dramatic therapeutic effect on the family member (commonly the mother) who is there to witness it. "I wish this test was done on all "epileptic" children', said one relieved mother recently. 'I have been nursing patients in mental hospitals for years and would not have known this was not a grand mal unless I had seen it happen with my own eyes'. Apart from the joy of positively knowing that the child does not have epilepsy, another therapeutic feature is the demonstration to the mother that the child's heart has already restarted by the time the seizure is at its worst. Not only parents, but referring doctors need to be convinced, and the more asystole the greater the impact.

Finally, as one does not wish to frighten the child by several attempts of increasing duration (not knowing whether very brief ocular compression will lead to a sufficiently persistent asystole to be of diagnostic value), it seems kindest to restrict the test to a single standardised 10 -second compression. This we have now done without regret on more than a thousand occasions.

J. B. P. STEPHENSON Royal Hospital for Sick Children, Yorkhill, Glasgow G3 8SJ

\section{Hepatic dysfunction and dysgammaglobulinaemia in Shwachman-Diamond syndrome}

Sir,

In the paper by Brueton et al. (Archives, 1977, 52, 76) it is pointed out that hepatic involvement should be regarded as a feature of Shwachman-Diamond syndrome (SDS). We should like to report an additional case of liver dysfunction in a patient with pancreatic achylia, dysgammaglobulinaemia, and metaphyseal dysostoses.

The patient was referred to our clinic from the welfare centre at age 10 months because of failure to thrive. He was fully breast fed up to 6 months and partly to 8 